\title{
What factors determine phenotype of cerebral autosomal dominant arteriopathy with subcortical infarcts and leukoencephalopathy (CADASIL)? Considerations in the context of a novel pathogenic $\mathrm{R} 110 \mathrm{C}$ mutation in the NOTCH3 gene
}

\author{
Dorota Dziewulska ${ }^{1,2}$, Dorota Sulejczak ${ }^{3}$, Michalina Wężyk ${ }^{4}$ \\ ${ }^{1}$ Department of Neurology, Medical University of Warsaw, Warsaw, ${ }^{2}$ Department of Experimental and Clinical Neuropathology, \\ Mossakowski Medical Research Centre, Polish Academy of Sciences, Warsaw, ${ }^{3}$ Department of Experimental Pharmacology, \\ Mossakowski Medical Research Centre, Polish Academy of Sciences, Warsaw, ${ }^{4}$ Laboratory of Neurogenetics, Mossakowski Medical \\ Research Centre, Polish Academy of Sciences, Warsaw, Poland
}

\begin{abstract}
We report patients from a Polish family with cerebral autosomal dominant arteriopathy with subcortical infarcts and leukoencephalopathy (CADASIL) who possess a novel heterozygous R110C mutation in exon 3 of the NOTCH3 gene leading to stereotypical cysteine loss. The proband had only seizure attacks and her magnetic resonance imaging (MRI) showed very numerous hyperintense foci in the cerebral white matter in a location characteristic of CADASIL. Distinctive ultrastructural assessment of vessels from skin-muscle biopsy revealed only mild degenerative changes but relatively numerous homogeneous deposits of granular osmiophilic material (GOM). In the other symptomatic family members with the same mutation ischaemic strokes were present but not epilepsy. In the proband's affected brother at a similar age, the brain MRI was normal but vessels showed pronounced degenerative changes and irregular GOM deposits. The present report not only extends the list of known pathogenic mutations responsible for CADASIL but also emphasizes clinical and morphologic variability among family members with the same NOTCH3 mutation, suggesting that probably additional factors, not only mutations, may influence the disease phenotype.
\end{abstract}

Key words: CADASIL, GOM, microangiopathy, NOTCH3, seizures.

\section{Introduction}

Cerebral autosomal dominant arteriopathy with subcortical infarcts and leukoencephalopathy (CADASIL) is due to mutations in the NOTCH3 gene, but its pathomechanism is still unclear in spite of a growing number of new findings concerning its pathogenesis $[3,9,12]$.
Clinical manifestations of the disease include migraine with or without aura, recurrent ischaemic strokes, psychiatric disorders and cognitive decline. There is no genotype-phenotype correlation between certain NOTCH3 mutations and CADASIL symptoms, and therefore it is a challenge for researchers to find 
an explanation for CADASIL's extremely variable symptomatology. The disease is diagnosed on the basis of genetic examination and/or results of ultrastructural assessment of vessels in skin/muscle material. Unfortunately, despite progress in neurodiagnostics, CADASIL is still under-recognized or diagnosed post mortem [19]. We report a CADASIL patient with epilepsy as a single and early clinical symptom and other symptomatic family carriers of the same novel NOTCH3 mutation with different clinical and ultrastructural phenotypes.

\section{Material and methods}

The clinical history of the examined family disclosed symptoms characteristic of CADASIL in 4 members ( 2 men and 2 women) in three generations (Fig. 1). Genetic testing for CADASIL performed in the proband, her father and brother revealed a novel R110C mutation in exon 3 of the NOTCH3 gene. In silico analysis showed that the mutation might be pathogenic. The mutation was probably passed on from the proband's grandmother (Fig. 1 I-2).

\section{Proband, a 36-year-old woman}

\section{(Fig. 1, III-8)}

The previously healthy woman was admitted to hospital at the age of 34 years after the first in her life tonicclonic seizure attack. The EEG record revealed polymorphic theta and delta waves in both temporal lobes. Neurologic examination of the patient was normal, as were results of her brain CT scan, Doppler examination of the extra- and intracranial arteries, cerebrospinal fluid analysis, MRI of the cervical spinal cord, ECG Holter, psychological examination, and routine biochemical tests. Nonspecific changes in brain MR spectroscopy were observed. Brain MRI revealed in T2 projection and FLAIR images numerous hyperintense foci and confluent hyperintensities in the cerebral white matter including both anterior temporal lobes (Fig. 2) and external capsules. In differential diagnosis CADASIL was taken into consideration; therefore skin-muscle biopsy and genetic examination of the NOTCH3 gene were performed.

\section{Proband's brother - a 38-year-old man (Fig. 1, III-9)}

At the age of 33 years he had the first ischaemic attack with transient hemiparesis and aphasia. His only brain MRI scan performed at that time was normal. Then he had a few minor episodes of transient ischaemic attacks without any permanent neurological deficits.

\section{Proband's father - a 61-year-old man (Fig. 1, II-3)}

At the age of 44 years he had the first ischaemic stroke of the left cerebral hemisphere without permanent neurological deficit. The strokes repeated twice at the ages of 50 and 60 years, resulting in persistent right-sided spastic hemiparesis, mild aphasia and cognitive disturbances. There were neither migraine, mood disturbances nor seizure attacks in his medical history.

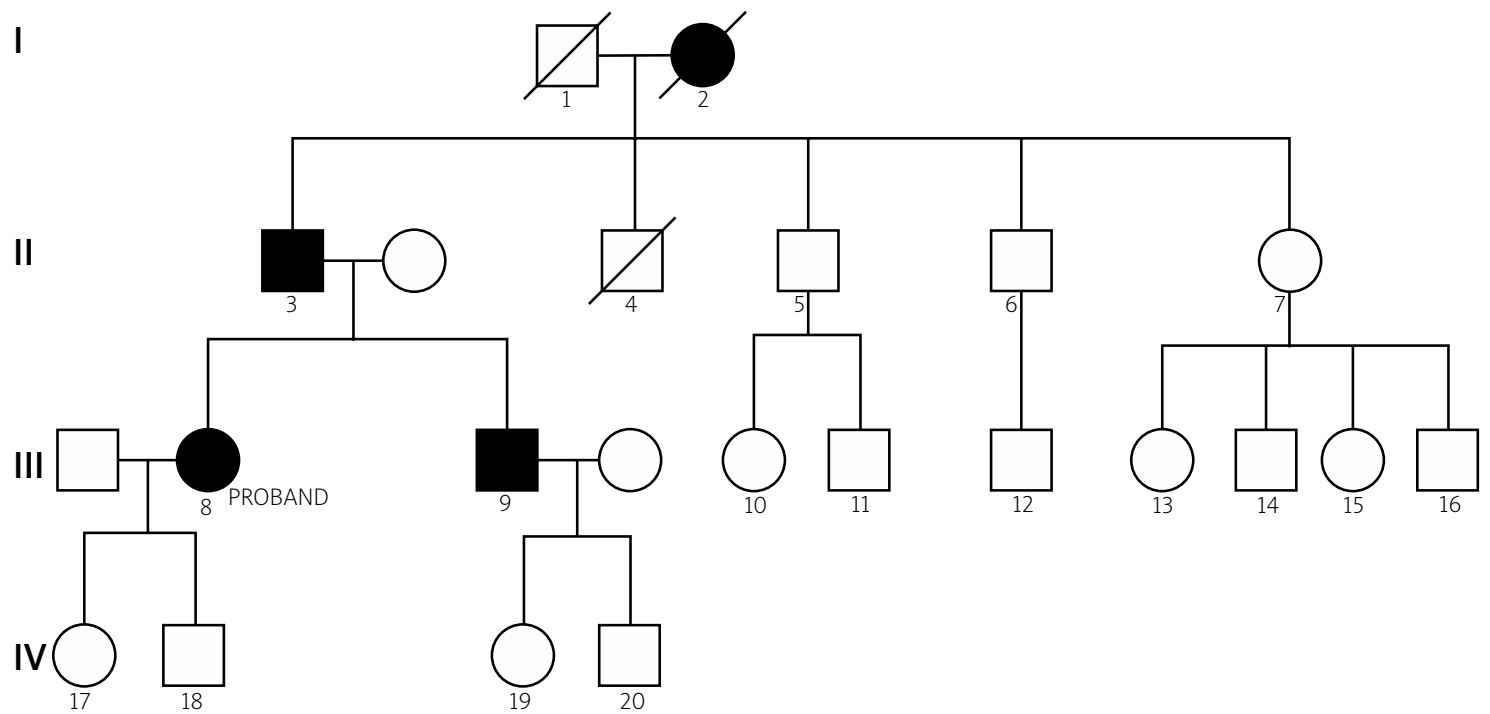

Fig. 1. Pedigree of the family with R110C mutation in the NOTCH3 gene; generations I-IV. 

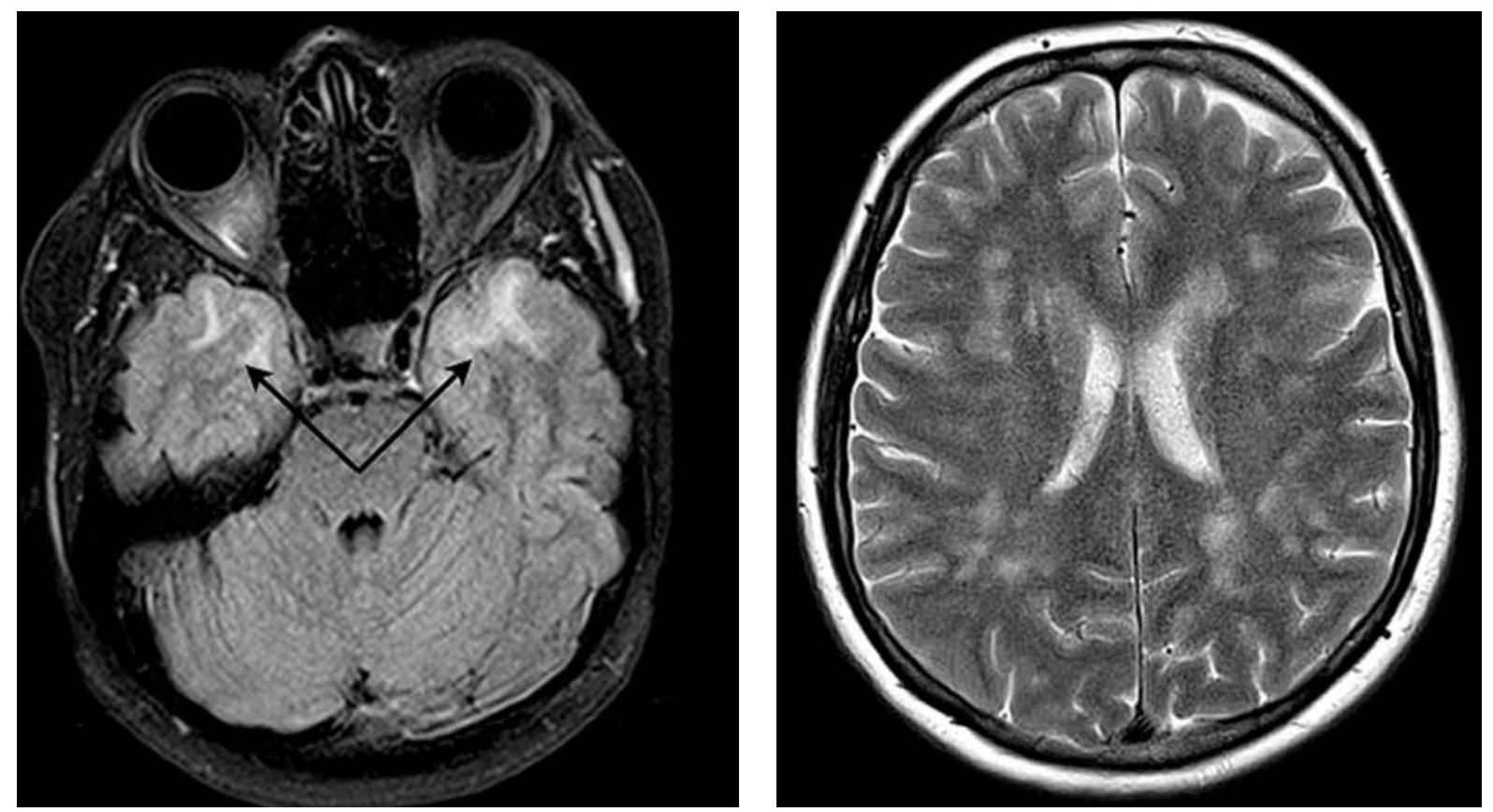

Fig. 2. Proband's MRI scans. In T2 projection there are visible focal and confluent hyperintense changes in the cerebral white matter, also involving both anterior temporal lobes (arrows).

Biopsy was not performed but genetic examination showed R110C mutation in the NOTCH3 gene.

\section{Proband's grandmother (Fig. 1, I-2)}

She died at the age of 48 years due to ischaemic stoke. In her medical history headaches and migraine were present but not seizure attacks.

\section{Results}

The ultrastuctural examination of vessels in skin-muscle biopsies material from proband and proband's brother was performed.

In proband ultrastructural examination of vessels revealed pathognomonic for CADASIL deposits of granular osmiophilic material (GOM) in arterial media and capillary basal membrane (Fig. 3A-B). Vessels with GOMs were not numerous but when the deposits were found their number was relatively abundant. GOM deposits were round or oval, homogenously osmiophilic, and located mainly in indentations of VSMC/pericyte cell membrane. Except the presence of GOMs, vessel appearance was generally normal e.i. neither VSMC/pericyte degeneration or loss nor thickening of the basal lamina was observed.

In skin-muscle biopsy of proband's brother, a relatively abundant pathological vessels at advanced stage of degenerative process and GOM deposits were found.
The affected vessels were often collapsed, and showed thickened basal lamina (Fig. 3D-E), endothelial and myocyte/pericyte vacuolization (Fig. 3C-E), cell shrinkage with abnormal nuclei and lucent enlarged mitochondria. GOM deposits were both regularly shaped and uniformly electron-dense as well as irregular and inhomogeneously dense (Fig. 3C-F). The latter were a bit more numerous. They were situated rather more distant from the cells within the basement membrane, and sometimes GOMs were observed even in vessels without visible VSMC/pericytes.

\section{Discussion}

Recently, an increasing number of pathogenic NOTCH3 mutations have been described. In some of these reports the authors emphasized phenotypic variability of the disease even among family members with the same mutation [18] or monozygotic twins [11]. Our article on a CADASIL family with a novel R110C mutation joins that group of publications. The affected family members, especially the proband and her brother, who are of similar age, showed different brain MRI scans, dissimilar clinical symptomatology, and diverse ultrastructural vascular changes.

In the course of CADASIL, epilepsy is usually secondary to stroke and rarely appears early $[2,13]$. The aeti- 

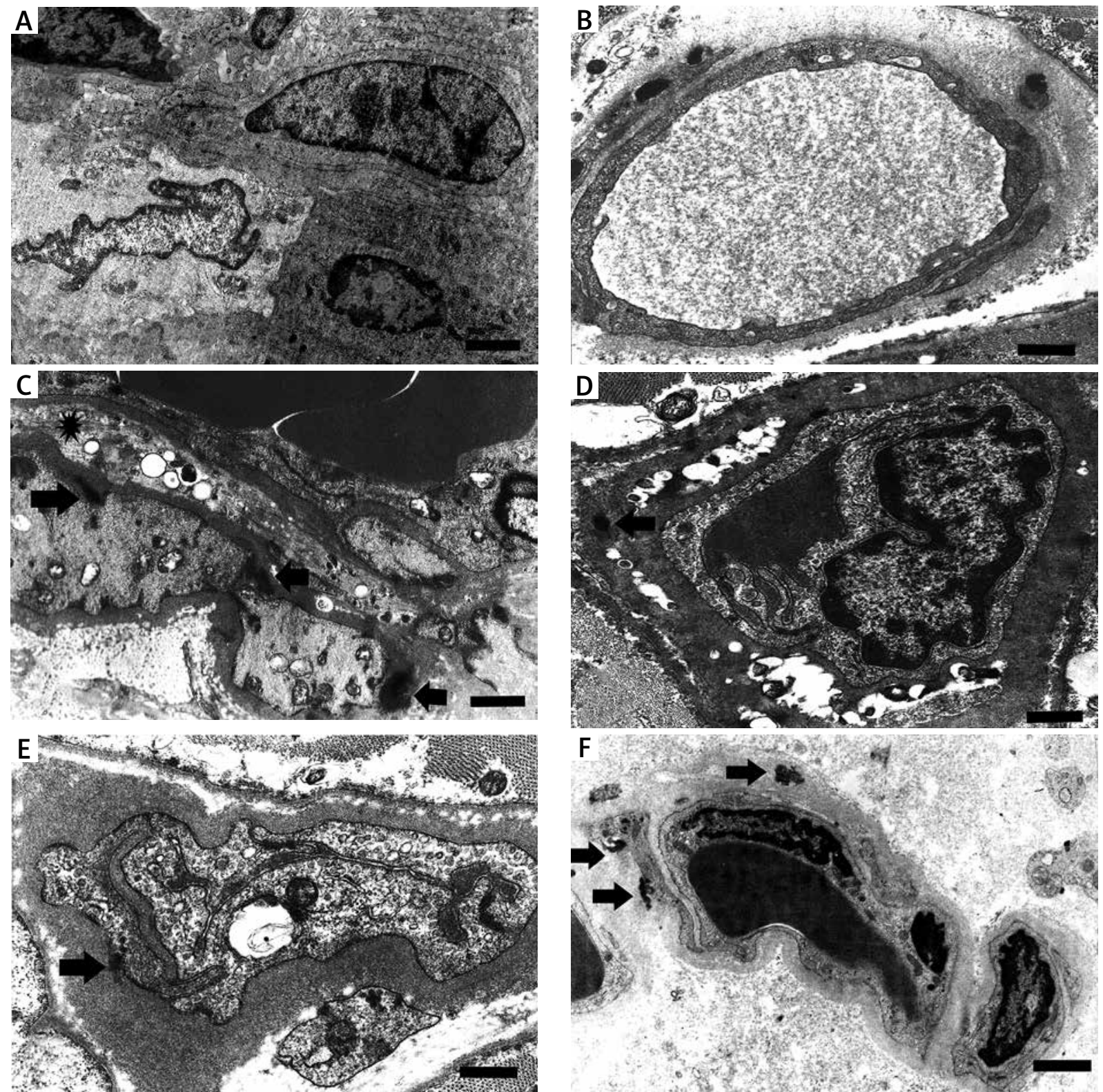

Fig. 3. Ultrastructural vascular changes in proband's (A, B) and her brother's (C-F) biopsy materials. A) Affected myocyte with pale cytoplasm and irregular nucleus in the arterial tunica media, bar $-2 \mu \mathrm{m}$. B) Normal appearance of capillary vessel with numerous dark, dense, and oval GOM deposits near pericytic processes, bar - $500 \mathrm{~nm}$. C) Vacuolar degeneration of VSMC (asterisk). In the media irregularly shaped and dense GOM deposits are visible (arrows), bar - $1 \mu \mathrm{m}$. D) Vacuolar degeneration of pericytes. In the thickened basal lamina a single GOM deposit is visible (arrow), bar $-500 \mathrm{~nm}$. E) Capillary vessel with thickened basal lamina and very narrow vessel lumen. Visible are clear, enlarged endothelial cells with various-sized vacuoles and a single GOM deposit (arrow), bar $-500 \mathrm{~nm}$. F) Atypical longitudinal GOM deposits in the wall of capillary vessel (arrows), bar - $500 \mathrm{~nm}$.

ology of epileptic seizures in CADASIL is still a matter of debate. Epileptogenic changes could be triggered by ischaemic brain lesion, but in the proband neither clinical nor neuroimaging findings indicated ischaemic stroke. They may also be associated with brain damage of a different mechanism than an ischaemic stroke. MRI hyperintensities in the temporal pole of CADASIL patients can be explained by enlarged perivascular 
space and degeneration of myelin accompanied by lack of drainage of the interstitial fluid [20]. Also, epilepsy in CADASIL may be directly related to altered properties of the Notch 3 signalling system [17]. In temporal lobe epilepsy, Notch signalling was activated both in an induced epilepsy model and in human epileptogenic tissues, and the effects of activated Notch signalling on seizures can be attributed to its regulatory role in excitatory synaptic activity in pyramidal neurons [16]. It is also known that some regions of the brain are more epileptogenic than others, and abnormalities in the anterior temporal regions are especially associated with epileptogenesis. Hyperintensities in the anterior temporal white matter visible in MRI are frequently observed in patients with a CADASIL diagnosis. Moreover, patients with temporal lobe epilepsy sometimes also have white matter abnormalities in the anterior temporal lobe [1]. In the proband, both MRI scans and the EEG record revealed pathological changes in the temporal lobes. These findings, in the context of the above data, can confirm the hypothetical origin of her epilepsy in the temporal lobes.

\section{Diverse ultrastructural changes in vessels of skin biopsies}

In the proband's skin-muscle biopsy, the appearance of vessels containing GOM deposits was normal, and only very few of them exhibited mild pathological changes. In contrast, in the biopsy of the proband's brother numerous vessels at an advanced stage of degeneration and with GOM deposits of various morphology were found. There are two main types of GOM: uniformly electron-dense deposits and mixed ones with inhomogeneous morphology $[7,8]$. Based on our previous studies on CADASIL we have suggested that GOM deposits can be formed on the surface of VSMC/pericytes, can penetrate from the cell into the basement membrane, and then can disperse in the extracellular matrix [7]. Although qualitative or semi-quantitative changes in GOM do not correlate directly with patients' age [10], there are some data indicating a possible relationship of the deposits with progression of histopathological changes in CADASIL. GOM deposits are very early alterations whose development precedes detectable morphological changes in cerebral vessels [4] but not their dysfunction [14]. In a human fetus with a mutated NOTCH3 gene, GOM deposits were not found [5], but they started to be observed in patients at the age of 20 years [6], and then, after a period in which the num- ber GOM deposits was relatively constant, their number gradually decreased with duration of the disease. These dynamics imply that GOM deposits as aberrations secondary to alterations in the Notch 3 signalling pathway may mirror - to a certain extent - activity of the pathological process in CADASIL. Effects of the Notch 3 signalling system are context- and cell-dependent, and therefore there are various factors influencing the results of its action. Additionally, the NOTCH3 gene is highly variable. Since these genetic variations play a role in age-related cerebral small vessel diseases [15], they may also have some impact on CADASIL.

In summary, since the diversity of clinical and morphological pictures of individuals with CADASIL falls within the disease spectrum, there are probably other factors than just NOTCH3 mutations that influence its phenotype.

\section{Disclosure}

Authors report no conflict of interest.

\section{References}

1. Adachi Y, Yagishita A, Arai N. White matter abnormalities in the anterior temporal lobe suggest the side of the seizure foci in temporal lobe epilepsy. Neuroradiol 2006; 48: 460-464.

2. Dichgans M, Mayer M, Uttner I, Brüning R, Müller-Höcker J, Rungger G, Ebke M, Klockgether T, Gasser T. The phenotypic spectrum of CADASIL: clinical findings in 102 cases. Ann Neurol 1998; 44: 731-739.

3. Dziewulska D, Nycz E. Abnormal integrin expression in the vascular media in CADASIL. Folia Neuropathol 2016; 54: 375-381.

4. JoutelA, Monet-Leprêtre M, GoseleC, Baron-MenguyC,HammesA, Schmidt S, Lemaire-Carrette B, Domenga V, Schedl A, Lacombe P, Hubner N Cerebrovascular dysfunction and microcirculation rarefaction precede white matter lesions in a mouse genetic model of cerebral ischemic small vessel disease. J Clin Invest 2010; 120: 433-445.

5. Lesnik Oberstein SA, Maat-Schieman ML, Boon EM, Haan J, Breuning $\mathrm{MH}$, van Duinen SG. No vessel wall abnormalities in a human foetus with a NOTCH 3 mutation. Acta Neuropathol 2008; 115: 369-370.

6. Lesnik Oberstein SA, van Duinen SG, van den Boom R, MaatSchieman ML, van Buchem MA, van Houwelingen HC, Hegeman-Kleinn IM, Ferrari MD, Breuning MH, Haan J. Evaluation of diagnostic Notch 3 immunostaining in CADASIL. Acta Neuropathol 2003; 106: 107-111.

7. Lewandowska E, Dziewulska D, Parys M, Pasennik E. Ultrastructure of granular osmiophilic material deposits (GOM) in arterioles of CADASIL patients. Folia Neuropathol 2011; 49: 174-180.

8. Lorenzi T, Ragno M, Paolinelli F, Castellucci C, Scarpelli M, Morroni M. CADASIL: Ultrastructural insights into the morphology of granular osmiophilic material. Brain Behavior 2017; 7: e00624. 
9. Mašek J, Andersson ER. The developmental biology of genetic Notch disorders. Development 2017; 144: 1743-1763.

10. Morroni M, Marzioni D, Ragno M, Di Bella P, Cartechini E, Pianese L, Lorenzi T, Castellucci M, Scarpelli M. Role of electron microscopy in the diagnosis of CADASIL syndrome: a study of 32 patients. PLoS One 2013; 17: e65482.

11. Mykkänen K, Junna M, Amberla K, Bronge L, Kääriäinen H, Pöyhönen M, Kalimo H, Viitanen M. Different clinical phenotypes in monozygotic CADASIL twins with a novel NOTCH3 mutation. Stroke 2009; 40: 2215-2218.

12. Nagatoshi A, Ueda M, Ueda A, Tasaki M, Inoue Y, Ma Y, Masuda T, Mizukami M, Matsumoto S, Kosaka T, Kawano T, Ito T, Ando Y. Serum amyloid P component: A novel potential player in vessel degeneration in CADASIL. J Neurol Sci 2017; 379: 69-76.

13. Oh JH, Kang BS, Choi JC. CADASIL. Initially Presented with a Seizure. J Epilepsy Res 2016; 6: 104-106.

14. Ruchoux MM, Domenga V, Brulin P, Maciazek J, Limol S, Tournier-Lasserve $E$, Joutel A. Transgenic mice expressing mutant Notch3develop vascular alterations characteristic of cerebral autosomal dominant arteriopathy with subcortical infarcts and leukoencephalopathy. Am J Pathol 2003; 162: 329-342.

15. Schmidt H, Zeginigg M, Wiltgen M, Freudenberger P, Petrovic K, Cavalieri M, Gider P, Enzinger Ch, Fornage M, Debette S, Rotter JI, Ikram MA, Launer LJ, Schmidt R. Genetic variants of the $\mathrm{NOTCH} 3$ gene in the elderly and magnetic resonance imaging correlates of age-related cerebral small vessel disease. Brain 2011; 134: 3384-3397.

16. Sha L, Wu X, Yao Y, Wen B, Feng J, Sha Z, Wang X, Xing X, Dou W, Jin L, Li W, Wang N, Shen Y, Wang Y, Wu L, Xu Q. Notch Signaling Activation Promotes Seizure Activity in Temporal Lobe Epilepsy. Mol Neurobiol 2014, 49: 633-644.

17. Valko PO, Siccoli MM, Schiller A, Wieser HG, Jung HH. Non-con vulsive status epilepticus causing focal neurological deficits in CADASIL. J Neurol Neurosurg Psych 2007; 78: 1287-1289.

18. Vyshka G, Kruja J. Clinical variability of the cerebral autosomal-dominant arteriopathy with subcortical infarcts and leukoencephalopathy phenotype in two siblings of a large family showing the same mutation. Int Med Case Rep J 2013; 6: 59-63.

19. Wesołowski W, Dziewulska D, Koziarska M, Iżycka-Świeszewska E. Cerebral autosomal dominant arteriopathy with subcortical infarcts and leukoencephalopathy (CADASIL) - literature review apropos an autopsy case. Pol J Pathol 2015; 66: 323-329.

20. Yamamoto Y, Ihara M, Tham C, Low RW, Slade J, Moss T, Oak ley AE, Polvikoski T, Kalaria RN. Neuropathological Correlates of Temporal Pole White Matter Hyperintensities in CADASIL. Stroke 2009; 40: 2004-2011. 